\title{
Pre COVID-19 usage of smartphones and medical applications among medical students
}

\author{
Hammad Ahmed Butt ${ }^{1 *}$, Waqas Ali², Warda Hussain ${ }^{3}$, Amaidah Mir, \\ Waleed Ahmed Butt ${ }^{5}$, Manahil Zulfiqar ${ }^{1}$
}

\begin{abstract}
${ }^{1}$ Department of Pharmacology, ${ }^{2}$ Department of Orthopaedics, ${ }^{3}$ Department of Pathology, ${ }^{4}$ Department of Anatomy, ${ }^{5}$ Department of Medical Education, CMH Kharian Medical College, Kharian, Punjab, Pakistan
\end{abstract}

Received: 07 April 2021

Revised: 17 April 2021

Accepted: 21 April 2021

\section{*Correspondence:}

Dr. Hammad Ahmed Butt,

Email: hammad034@gmail.com

Copyright: (C) the author(s), publisher and licensee Medip Academy. This is an open-access article distributed under the terms of the Creative Commons Attribution Non-Commercial License, which permits unrestricted non-commercial use, distribution, and reproduction in any medium, provided the original work is properly cited.

\begin{abstract}
Background: To determine awareness of medical students that utilize smartphone and their familiarity of medical applications.

Methods: The questionnaire-based descriptive study was conducted in December 2019 and comprised medical students of first year and second year of the CMH Kharian Medical College, Kharian, and Nawaz Sharif Medical College, Gujrat, Gujranwala Medical College, Gujranwala and Mohi-ud-Din Islamic Medical College, Mirpur. Questionnaires were distributed in the classrooms and were filled by the students anonymously. SPSS 20 was used for statistical analysis.

Results: Among the 770 medical students in the study, 747 (97\%) had smartphones and 23 (3\%) were using simple cell phones. Overall, $362(47 \%)$ of the smart phone users were using some medical apps. Besides, 223 (29\%) were aware of the medical apps but were not using them. Also, $655(85 \%)$ students were not using any type of medical text eBooks through their phone, and only $115(15 \%)$ had relevant text eBooks in their phones.

Conclusions: A very low awareness among medical college students exists regarding smartphones as a gadget for improving medical knowledge.
\end{abstract}

Keywords: E-books, Medical applications, Smartphone, Medical students

\section{INTRODUCTION}

Smart phone apps are becoming increasingly popular among Medical students. These apps have also revolutionized the medical field. ${ }^{1}$ Applications in smartphones are being used for clinical guidelines, as medical calculators, drug reference tools, textbooks, and research search portals. There are mobile apps which can simulate surgical procedures and help in medical examination such as hearing and visual tests. ${ }^{2,3}$ In 2017, there were 325,000 health apps available from 84,000 health app publishers, with about 78,000 apps added in the last year and by $202046 \%$ of clinicians plan to use medical apps. ${ }^{4-6}$ In a study conducted in United Kingdom, $84 \%$ of the medical students said that smart devices were a useful addition to their education. ${ }^{7}$ The benefits of these apps are better management of time and information, maintenance of record, better communication and consultations, medical education, medical training and clinical decisionmaking.8 So medical students have found mobile devices as a tool to supplement their education, with access to etextbooks, simulation tools and similar medical references. ${ }^{9,10}$ The aim of this study conducted was to analyze the usage and popularity of medical apps among medical students and their perceptions on app usage. For this purpose, we conducted a cross sectional study, handed out a questionnaire, and analyzed the overall use of digital media in medical education. 


\section{METHODS}

The questionnaire-based descriptive cross-sectional study was conducted in in December 2019 and comprised medical students of four different medical colleges. Which includes $\mathrm{CMH}$ Kharian Medical College, Kharian, Mohiud-Din Islamic Medical College, Mirpur, Nawaz Sharif Medical College, Gujrat and Gujranwala Medical College, Gujranwala. The first two are private sector medical colleges whrereas the next two are public sector medical college. The sample size was calculated by using the World Health Organisation (WHO) calculator with confidence level of $95 \%$, absolute precision $0.03 \%$ and $\mathrm{p}=95 \% .^{11}$

The questionnaire was constructed by the lead researcher and reviewed by an expert panel for content reliability and validity. Previous literature and researchers' personal experiences were used to form and phrase the questions. ${ }^{2,12}$

Inclusion criteria included only English-speaking individuals as the survey was in English only and all the medical students of 1st year and 2nd year of CMH Kharian Medical College, Kharian, Mohi-ud-Din Islamic Medical College, Mirpur, Nawaz Sharif Medical College.

Exclusion criteria excluded all the non - English speaking individuals as the survey was in English only and medical college students of other colleges than included in inclusion criteria. There were no inclusion or exclusion criteria based on specialty, race/ethnicity, or gender.

The questionnaires were distributed in classrooms and were filled up by the students keeping their names incognito. The questions related to the usage of smart phones, type of smart phone being used, awareness of any medical apps, name of the apps, awareness of any medical books, time spent on medical apps, purpose of using medical apps.

Statistical package for social sciences (SPSS) 20 was used for statistical analysis. Frequencies and percentages were calculated for categorical variables and mean and standard deviations were calculated for numerical variables. Descriptive statistics were used for all continuous variables.

The questionnaires were distributed in classrooms and were filled up by the students keeping their names incognito. The questions related to the usage of smart phones, type of smart phone being used, awareness of any medical apps, name of the apps, awareness of any medical books, time spent on medical apps, purpose of using medical apps.

SPSS 20 was used for statistical analysis. Frequencies and percentages were calculated for categorical variables and mean and standard deviations were calculated for numerical variables. Descriptive statistics were used for all continuous variables.

\section{RESULTS}

In our study 770 students took part in a survey to determine the usage of applications by medical students. About 70 percent of the students were females $(\mathrm{N}=497)$, whereas $30 \%$ were males $(\mathrm{N}=213)$ who took part in the study. Average age of participants was 20.15 years $(\mathrm{SD}=1.010$, range 18-23). About $747(97 \%)$ of the students acknowledged the use of smartphone. About $616(80 \%)$ of students were in possession of an android phone, while 131 (17\%) were using an apple phone. Only 23(3\%) of the users were in possession of a simple cellphone. $508(66 \%)$ of the respondents said that they preferred to use non digital means of learning over digital means of learning (Table 1).

Table 1: Demographic detail of participants.

\begin{tabular}{|ll|}
\hline Students demographic data & $\begin{array}{l}\text { Study population } \\
(\mathrm{n}=770)\end{array}$ \\
\hline Mean age (years) & $20.15( \pm 1.010)$ \\
\hline Sex (female) & $64.5 \%$ \\
\hline Smartphone users \% & $97 \%$ \\
\hline Types of users & \\
\hline Android user & $80 \%$ \\
\hline Awareness of Medical apps & $76 \%$ \\
\hline $\begin{array}{l}\text { Installed Medical Apps } \\
\text { Students recommended } \\
\text { medical App }\end{array}$ & $47 \%$ \\
\hline
\end{tabular}

Total 585 (76\%) students accepted having awareness regarding medical smartphone applications. Less than half $362(47 \%)$ of all the students in survey had installed medical/learning smartphone applications. Only 208 (27\%) of the students told being recommended a smartphone application by a medical educator Table 1 .

Around 385 (50\%) of the students reported using lecture slides to study throughout the academic year. Less than $30 \%$ students 229 reported usage of smartphone apps throughout the academic year. About (75\%) 577 of students reported saying that they use self-written notes to study throughout the academic year. More than $80 \% 617$ students use textbooks to study throughout the year. 408 (53\%) students have said to be using internet search for study throughout the academic year. Less than $40 \%$ of students 307 reported using e-learning sources for study. Around $75 \% 577$ students are using short books to study as per our study. $570(74 \%)$ students use exam questions throughout the academic year to study. Only $27035 \%$ students utilized e-books to study throughout the academic year.

Sources of study material during exam days were also asked about in the study. Nearly $384(50 \%)$ of the students consulted lecture slides around exam days. Only $231(30 \%)$ of students have consulted smartphone applications during exam days. $539(70 \%)$ of students used their written notes for study during exam days. $593(77 \%)$ of the students utilize textbooks for study during exam days. Nearly half of the students have accepted using internet search for 
study. Only $231(30 \%)$ have accepted usage of e-learning. Only $485(63 \%)$ students use textbooks (less than 300 pages) during exam days. Results show 555 (72\%) of students utilize previous exam questions. While $270(35 \%)$ consult e-books for study during exam days.

Among the users of medical applications on smartphones only $216(29 \%)$ used apps for revision study. 134 (18\%) admitted using medical applications to prepare a presentation. $269(36 \%)$ of the medical students used smartphone to look up medical information. $105(14 \%)$ students had accessed medical journals using smartphones. Around 164 (22\%) students accessed medical news on their smartphones. $112(15 \%)$ students used smartphones to look up information regarding a drug. A low 112 (15\%) of the students had a textbook on their smartphone.

No preference was seen in regard to obtaining medical applications. About $362(47 \%)$ of the students disagree either strongly or simply regarding learning from medical applications. More than half of the students consider medical applications inferior to books and don't think medical apps will replace books in the future. While most $308(40 \%)$ are not even in favour of medical applications supplementing books.

\section{DISCUSSION}

The focus of medical education in an era of COVID pandemic has largely shifted from classrooms to hand held devices. This shift is quite drastic and was largely unprecedented. Our study conducted just before COVID pandemic, as it was about to bloom, might be a checkpoint of how this shift has taken place. Another study, in line with ours can be conducted which highlights the current usage of smartphones and applications during COVID pandemic.

Over the last two decades mobile phone technology innovations have led to changes in our lives in every way possible, making our daily task convenient and less meticulous. Due to these hand-held devices, we are now able to attain deeds previously considered to be too much tedious. ${ }^{1}$ This has made insights in every facet of our daily activities and even making life easier during our leisure. Mobile phones took a radical curve with the launch of the smartphone in $1994 .{ }^{13}$ Since then mobiles have gradually become an indispensable associate for our day-to-day activities. ${ }^{14}$ This fact is revealed in our studies in which 97\% respondents had smartphones and only $3 \%$ were using simple phones. This comes out to be interesting when compared with a US based study done on medical students which reported a clear divide in about $52 \%$ between preclinical and clinical years (28\% and $76 \%$ respectively). ${ }^{7}$ One British study in contrast showed equal smartphone ownership with pre-clinical and clinical years $(76 \%$ and $80 \%$ respectively). ${ }^{12}$ Smartphone usage even in UK based community is less compared to our study. ${ }^{12}$
Less than half $362(47 \%)$ of all the students in survey had installed medical/learning smartphone applications which is in contrast to the study carried out in Saudi Arabia where $97 \%$ (320) of the participants were well aware of different medical apps for smart devices and a vast majority $89.1 \%$ (294) had installed different medical apps on their smart devices. ${ }^{1}$

The British study showed that $83.3 \%$ of smartphone users use used medical apps with $47 \%$ of them using it for educational purposes. ${ }^{12}$ Contrary to above mentioned studies, only $362(47 \%)$ smartphone users were using any medical apps and 408 (53\%) were just using it for social media in our study.

A total 134 (18\%) admitted using medical applications to prepare a presentation. The majority of the participants used the medical apps for either revision of their courses $(62.4 \%)$ or for accessing medical information (67.3\%). Other noticeable uses of medical apps were for preparing a presentation $(34.5 \%){ }^{1}$

A similar study conducted locally in Karachi, Pakistan, showed a smartphone ownership of $65.7 \%$ amongst postgraduate Residents, which is much less than our study. The plausible thing in the same study was that despite a lower number of smartphone ownership, its academic usage was much higher $(85.7 \%)$ than our study. ${ }^{15}$

It was surprising that $465(62.3 \%)$ students were not using any type of medical text e-books through their phones and only $282(37.7 \%)$ had relevant textbooks in their phones compared to one study that showed that $61 \%$ students used it for clinical handbooks.

One astonishing fact that was deduced from the study was that $747(100 \%)$ out of 747 had internet on their phones; $408(53 \%)$ had availability to the internet, but still were not using any type of medical information from their phones. A study done in Multan showed similar results in regards to internet usage among medical students. The study showed that $176(99 \%)$ out of 177 students had access to the internet but only $90(50.6 \%)$ used it for educational purposes. $^{16}$

Almost all our subjects had smartphones yet somehow, we were unable to see a positive usage of this expensive appliance in our study. A need for more studies is essential to figure out the core relationship between mobile, its applications in medical education, also its utility to medical students. In a modern pandemic the need for their integration is vital. Generally, this research opens avenues to create and suggest critical learning resources and activities for provision on smartphones and their applications.

Our study can be limited by self - selection bias and we did not include the perspective of the faculty in regards to medical application. We only conducted the study in a limited number of medical colleges, which might not be the 
complete picture of the study. Despite these limitations our data is a reference point for future studies. ${ }^{17-22}$

\section{CONCLUSION}

Modern day doctors lead very busy professional lives and their information requirements have increased over the years. To answer for the needs of the patient's physicians need the best information available so excellent health service can be provided. Smartphones and their applications are a modern tool for knowledge, monitoring and diagnosis in medical training. Our study revealed a high level of smartphone usage among medical students but highlights a lack of utility regarding medical applications. We suggest that students be trained in using such applications so that betterment of students is achieved. Accreditation of medical applications by institutions can also be helpful in their greater usefulness.

Funding: No funding sources

Conflict of interest: None declared

Ethical approval: The study was approved by the Institutional Ethics Committee

\section{REFERENCES}

1. Sayedalamin Z, Alshuaibi A, Almutairi O, Baghaffar M, Jameel T, Baig M. Utilization of smart phones related medical applications among medical students at King Abdulaziz University, Jeddah: A crosssectional study. Journal of infection and public health. 2016;9:691-7.

2. Matos J, Petri CR, Mukamal KJ, Vanka A. Spaced education in medicalresidents: an electronic intervention to improve competency and retention of medical knowledge. PLoS One. 2017;12:e0181418.

3. Kuperstock JE, Horný M, Platt MP. Mobile app technology is associated with improved otolaryngology resident in-service performance. Laryngoscope. 2019;129:E15-20.

4. Bauer M, Glenn T, Geddes J. Smartphones in mental health: a critical review of background issues, current status and future concerns. Int $\mathrm{J}$ Bipolar Disord. 2002;8(2).

5. Bates DW, Landman A, Levine DM. Health Apps and Health Policy: What Is Needed? JAMA. 2018;320(19):1975-6.

6. Survey: 46 percent of clinicians plan to use health apps in practices by 2020 . Available at: https://www.mobihealthnews.com/41489/survey-46percent-of-clinicians-plan-to-use-health-apps-inpractices-by-2020/. Accessed on $7^{\text {th }}$ March 2021.

7. Shah J, Haq U, Bashir A, Shah SA. Awareness of academic use of smartphones and medical apps among medical students in a private medical college? JPMA. J Pak Med Assoc. 2016;66(2):184-6.

8. Ventola CL. Mobile devices and apps for health care professionals: uses and benefits. Pharm Ther. 2014;39(5):356-64.
9. Lewis TL, Aungst TD, Hutchinson C. Radiology education, mobile technology and medical apps. BMJ Simul Technol Enhanc Learn. 2015;1(2):45-8.

10. Awais M, Rehman A, Baloch N. Use of portable gadgets in radiology clinical and academic activities: A questionnaire based, cross-sectional study. Journal of Pakistan Medical Association. 2019;69(6):868-8.

11. Lwanga SK, Lemeshow S. Sample size determination in health studies, A practical manual. World Health Organization. 1991;1-3. Accessed on $7^{\text {th }}$ March 2021.

12. Payne KB, Wharrad H, Watts K. Smartphone and medical related app use among medical students and junior doctors in the United Kingdom (UK): a regional survey. BMC Med Inform DecisMak. 2012;12:121.

13. Kwee CK, Jun KW, Sivasanggari S, Chithralekha V, LeeGY, Chun TN. Medical student's perceptions regarding theimpact of mobile medical applications on their clinicalpractice. JMTM. 2014;3(1):46.

14. Ho K, Lauscher H, Broudo M, Jarvis-Selinger S, Fraser J, Hewes D. The impact of a personal digital assistant (PDA)case log in a medical student clerkship. Teach Learn Med. 2009;21(4):318-26.

15. Bhatti R, Javed MW. Experience of internet utilization by post graduate students at Nishter Medical College, Multan, Pakistan. Library Philosophy and Practice. 2014;0-1.

16. Hafeez K, KaimKhani GM, Jawaid M, Bux M. Is smartphone a necessity or luxury among orthopedicspecialty?J Pak Med Assoc. 2014;64:27-9.

17. Mosa AS, Yoo I, Sheets L. BMC Medical Informatics and Decision Making. 2012;12:67.

18. Franko OI, Tirrell TF. Smartphone app use among medical providers in ACGME training programs. J Med Syst. 2012;36(5):3135-9.

19. Gill PS, Kamath A, Gill TS. Distraction: an assessment of smartphone usage in health care work settings. Risk Manag HealthC Policy. 2012;5:105-14.

20. Chen J, Park Y, Putzer GJ. An Examination of the Components that Increase Acceptance of Smartphones among Healthcare Professionals. Electron J Health Inform. 2010;5(2):37

21. Robinson T, Cronin T, Ibrahim H, Jinks M, Molitor T, Newman $\mathrm{J}$ et al. Smartphone use and acceptability among clinical medical students: a questionnairebased study. J Med Syst. 2013;37:9936.

22. Wallace S, Clark M, White J. 'It's On My iPhone': Attitudes to the Use of Mobile Computing Devices in Medical Education, A Mixed-Methods Study. BMJ Open. 2010;2(4):49.

Cite this article as: Butt HA, Ali W, Hussain W, Mir A, Butt WA, Zulfiqar M. Pre COVID-19 usage of smartphones and medical applications among medical students. Int J Basic Clin Pharmacol 2021;10:479-82. 